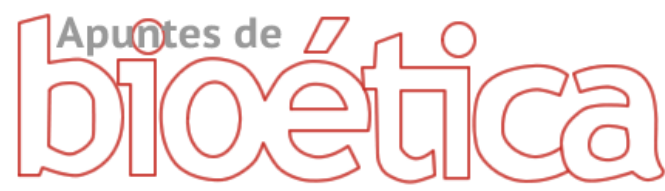

https://doi.org/10.35383/apuntes.v2i2.286

\title{
La objeción de conciencia del personal médico frente al aborto terapéutico regulado en el Protocolo de Aborto Terapéutico
}

\author{
Belú Fiorella Pérez Dávila ${ }^{1}$
}

\section{INFORMACIÓN DEL ARTÍCULO RESUMEN}

Historia del artículo:

Recibido el 23 de setiembre de 2019

Aceptado el 30 de diciembre de 2019

\section{Palabras claves.}

Libertad de conciencia

Objeción de conciencia

Vida humana

Aborto

Aborto terapéutico

Profesional médico
El Protocolo de Aborto Terapéutico (PAT), vigente desde el 2014, regula el procedimiento para la ejecución de abortos terapéuticos a nivel nacional. Establece una lista abierta de entidades clínicas para su acceso, bajo el Consentimiento Informado de la gestante y sin incluir los derechos de su hijo. Esta norma genera en el profesional médico la obligación de ejecutar abortos, lo cual puede contradecir los preceptos de su conciencia sobre el respeto indiscriminado de toda vida humana, restringiendo su derecho constitucional a la libertad de conciencia. En el presente artículo, analizamos el contenido de dicha libertad y el derecho a la Objeción de Conciencia, así como la coherencia entre el PAT y el Art. 119 del Código Penal (CP), para determinar si con esta norma tiene lugar la Objeción de Conciencia (O.C) del profesional médico a la ejecución de dicho aborto, por colisionar con su convicción profunda de respetar a toda vida humana, con independencia de su etapa de desarrollo humano.

The conscientious objection of medical personnel to therapeutic abortion regulated in the Therapeutic Abortion Protocol

\section{ABSTRACT}

\section{Keywords:}

Freedom of conscience

Conscientious objection

Human life

Abortion

Therapeutic abortion

Medical professiona
The Therapeutic Abortion Protocol (PAT), in force since 2014, regulates the procedure for the execution of therapeutic abortions nationwide. Establishes an open list of clinical entities for access, under the Informed Consent of the pregnant woman and not including the rights of her child. This rule generates in the medical professional the obligation to perform abortions, which may contradict the precepts of his conscience about the indiscriminate respect of all human life, restricting his constitutional right to freedom of conscience. In this article, we analyze the content of said freedom and the right to Conscientious Objection, as well as the coherence

\footnotetext{
1 Máster en Bioética por la Universidad de Navarra-España. Maestría en Persona, Matrimonio y familia. Universidad Católica Santo Toribio de Mogrovejo. Lima, Perú. Contacto: bperez.12@alumni.unav.es. ORCID: https://orcid.org/0000-0002-7734-9839
} 
between the PAT and Article 119 of the Criminal Code (CP), to determine if with this rule the Objection of Awareness (OC) of the medical professional to the execution of said abortion, for colliding with his deep conviction to respect all human life, regardless of his stage of human development.

\section{Introducción}

Pese al avance de la ciencia y tecnología médicas, en la práctica clínica aún hay situaciones en las que se presentan complicaciones en una mujer durante el embarazo, que pueden acarrear un riesgo grave para la vida de la madre gestante, o su salud, y la de su hijo.

Cuando la solución tomada conlleva a la muerte de la persona en formación gestacional, suele llamarse "aborto terapéutico". El mismo que se encuentra despenalizado en el Perú desde el año 1924 hasta la actualidad ${ }^{2}$. Esto significa que los profesionales de la salud pueden practicarlo cuando sea necesario, sin que ello implique la privación de su libertad. Sin embargo, el 27 de junio del 2014 entró en vigencia la Resolución Ministerial $\mathrm{N}^{\circ}$ 4862014/MINSA ${ }^{3}$, o conocida comúnmente como PAT. Regula el procedimiento para la realización de abortos a las madres gestantes en el marco de lo dispuesto en el Art. 119 del Código Penal. Para lo cual ha determinado que la mujer que padezca de alguna de las diez enfermedades establecidas en su art. 6 inc. 1, puede tener el acceso a la práctica abortiva. Esta norma, pese a su esfuerzo por enlistar las causales para tener acceso a un aborto por razones terapéuticas, entendiéndose indispensable, dado que es una norma que permite la muerte de una persona en su etapa pre natal, admite una lista indeterminada de enfermedades cuyo padecimiento daría lugar a

\footnotetext{
${ }^{2}$ Art. 119: "No es punible el aborto practicado por un médico con el consentimiento informado de la mujer embarazada o de su representante legal, si lo tuviere, cuando es el único medio para salvar la vida de la gestante o para evitar en su salud un mal grave y permanente

${ }^{3}$ Guía Técnica Nacional para la estandarización del procedimiento de la Atención Integral de la gestante en la Interrupción Voluntaria por indicación Terapéutica del Embarazo menor de 22 semanas con consentimiento informado en el marco de lo dispuesto en el artículo 119 del Código Penal. Resolución Ministerial N 486-2014/MINSA. Perú, 2014.
}

un aborto (art. 6 inc. 1. 114). Resulta necesario determinar el tipo de aborto que regula, ya que pese a su denominación como "terapéutico", en vista de dicha lista indeterminada que justifica la eliminación de una vida humana, es cuestionable.

Asimismo, desde su entrada en vigencia, el PAT genera la obligación de los profesionales médicos de practicárselo a la mujer que, bajo la justificación terapéutica, decida y consienta la realización de un aborto. Si este se realizara en coherencia con el Art. 119 del Código Penal y fuera efectivamente terapéutico, el médico podría aplicar su ciencia en favor de ambas vidas humanas, sin tener que buscar la muerte de un ser humano. De lo contrario, si se careciera de dicha coherencia, el médico podría encontrare ante un dilema ético: entre obedecer y realizar el aborto que regula el PAT y respetar la vida humana en desarrollo gestacional, en donde obedecer esta norma contravendría seriamente su consciencia. Es importante analizar dicha norma, a fin salvaguardar, los principios fundamentales que regula nuestra Constitución Política: vida humana y libertad de conciencia de los profesionales médico, mediante el ejercicio del derecho de la Objeción de Conciencia.

\section{Metodología}

Para la presente investigación, se ha recurrido a la revisión de diversas fuentes de información científica y jurídica. Hemos empleado la técnica del fichaje, que nos permitió una observación directa de cada punto que tratamos.

\footnotetext{
4 "...cualquier otra patología materna que ponga en riesgo la vida de la gestante o genere en su salud un mal grave y permanente".
} 
Nos hemos servido de las fichas bibliográficas, para conservar la información relevante del libro, enciclopedia, revista, entre otros, que contiene el tema que nos interesa, para poder ubicarlo en cualquier momento. Asimismo, hemos empleado tanto las fichas de resumen y textuales como las fichas de análisis y comentarios de documentos

\section{Resultados, análisis y discusión}

Nuestro análisis se enfoca la libertad de conciencia, la objeción de conciencia, el derecho, la protección jurídica de la vida del concebido en el Perú, el aborto terapéutico regulado en el PAT, a fin de poder determinar si tiene cabida la Objeción de Conciencia del profesional médico a la realización de abortos terapéuticos, según lo regulado en el PAT.

\section{Libertad de conciencia}

La libertad de conciencia es un derecho que procura el respeto de la dimensión individual de las personas en cuanto a sus convicciones personales. Esta libertad consiste en la facultad que tiene toda persona, entendida como un ser racional capaz de asumir los sentidos de su realidad al ser un sujeto autónomo (Mansilla y Villarán, 2000, p. 22), de tener y ejercer, exteriorizar, sus convicciones morales orientadas hacia el actuar recto, lo que implica una libertad tanto para creer o no creer lo que quiera en materia política, artística, filosófica, etc.; como para asumir un sentimiento o convicción con respecto a lo que considera real y de tener una opinión determinada (Sánchez, 2001. p, 206). Cuyo inverso consiste en el derecho a no ser obligado a comportarse en contra de ellas (Llamazares, 1997, p.15). Y el derecho a la libre formación de la conciencia.
Según Mansilla y Villarán (2000), la libertad de conciencia es una garante de la libertad en los Estados democráticos. En donde las leyes respaldan las libertades individuales, recordando que estas constituyen el contrato social a favor de la estabilidad política. Por ello resulta lógico que se le permita la objeción de una ley al ciudadano cuando el Estado incumple con sus deberes, sobre todo los de respetar los derechos fundamentales (pp. 46-47).

El Estado se encuentra imposibilitado de exigir o imponer conductas opuestas a dichos deberes contraídos con los individuos. Enseguida, si lo hace tendría que enfrentarse al derecho de todos a exigir el respeto del mencionado pacto, sufriendo las manifestaciones que esto implica a través de la objeción de conciencia.

Afortunadamente el derecho de libertad de conciencia es considerado como un derecho fundamental, reconocido en el Artículo 18 de la Declaración Universal de Derechos Humanos ${ }^{5}$, referido a la protección de una sola libertad individual o colectiva y referido a la capacidad de elección de una propia cosmovisión o concepción de la vida, es decir, al conjunto de creencias que sostienen al hombre. Asimismo, se encuentra protegida por el Art. 12 de la Convención Americana sobre Derechos Humanos de San José de Costa Rica, el cual regula el derecho de las personas a permanecer en sus propias creencias, manifestarlas con la limitación de la seguridad, el orden, la salud o la moral públicos o los derechos de los demás, el derecho de los padres a educar a los hijos conforme a sus propias religiones, cambiar de creencias y establece la prohibición de

\footnotetext{
5 "Toda persona tiene derecho a la libertad de pensamiento, de conciencia y de religión; este derecho incluye la libertad de cambiar de religión o de creencia, así como la libertad de manifestar su religión o su creencia, individual y colectivamente, tanto en público como en privado, por la enseñanza, la práctica, el culto y la observancia".
} 
medidas restrictivas para su ejercicio, y con similar contenido, la libertad de conciencia se encuentra normada por el Art. 18, el Pacto Internacional de Derechos Civiles y Políticos ${ }^{6}$.

El reconocimiento de los derechos tan íntimos de la persona, como la libertad de conciencia, parte de la consideración y el respeto por la persona humana (Mosquera, 2005. p.129). El derecho a la libertad de conciencia tiene como fundamento los atributos de la persona, cuyo origen está en su naturaleza. El Estado sólo reconoce a través de una norma jurídica estos derechos, no los crea. A decir de Hervada (2005) "la norma jurídica positiva no puede abrogar los mandatos y prohibiciones naturales; es decir, no puede destruir la obligatoriedad de la norma jurídica natural que prescribe o prohíbe una conducta" (p. 197). Las normas establecidas por el orden positivo no pueden por sí mismas ser guía autónoma de las conductas humanas.

En el Perú el derecho a la libertad de conciencia se ha desarrollado paulatinamente en dos momentos claramente diferenciables. En un primer momento su protección se inició desde una vertiente religiosa; tal y como se entiende de las Constituciones Políticas del Perú de 1823 (Art. 8) y 1860 (Art. 4) ${ }^{7}$. En un segundo

\footnotetext{
6 "1. Toda persona tiene derecho a la libertad de pensamiento, de conciencia y de religión; este derecho incluye la libertad de tener o de adoptar la religión o las creencias de su elección, así como la libertad de manifestar su religión o sus creencias, individual o colectivamente, tanto en público como en privado, mediante el culto, la celebración de los ritos, las prácticas y la enseñanza.

2. Nadie será objeto de medidas coercitivas que puedan menoscabar su libertad de tener o de adoptar la religión o las creencias de su elección.

3. La libertad de manifestar la propia religión o las propias creencias estará sujeta únicamente a las limitaciones prescritas por la ley que sean necesarias para proteger la seguridad, el orden, la salud o la moral públicos, o los derechos y libertades fundamentales de los demás.

4. Los Estados Partes en el presente Pacto se comprometen a respetar la libertad de los padres y, en su caso, de los tutores legales, para garantizar que los hijos reciban la educación religiosa y moral que esté de acuerdo con sus propias convicciones."

${ }^{7}$ Ambas Constituciones Políticas del Perú reconocieron el ejercicio general y único de la religión Católica, así lo prescribieron la Constitución Política de la República Peruana de 1823 en su Art. 8: "La religión de la República es la Católica, Apostólica, Romana", y la Constitución Política del Perú de 1860 en su Artículo 4, "La Nación profesa la Religión Católica, Apostólica, Romana: el Estado la protege". Ello fue modificado por la Ley 2193 del 11 de Noviembre de 1915, al derogar el Art. $4^{\circ}$ de la Constitución del año
}

momento ocurre la ampliación para su protección, como ocurrió con la Constitución de 1933 (Art. 59) se estableció que "La libertad de conciencia y de creencia es inviolable. Nadie será perseguido por razón de sus ideas". De similar forma se reconoció en el Art. 2 . Inc. 3 de la Constitución de 1979 con el siguiente tenor "Toda persona tiene derecho a la libertad de conciencia y de religión, en forma individual o asociada. No hay persecución por razón de ideas o creencias siempre que no ofenda a la moral o altere el orden público", lo cual se mantiene en nuestra Constitución actual (Art. 2 inc.3).

\section{Objeción de conciencia}

\section{A) Concepto de Objeción de Conciencia}

Existe una inexactitud a la hora de conceptualizar el derecho a la Objeción de Conciencia. Para unos autores como Mosquera (2005) se trata de un claro derecho fundamental (p.162), y para otros de un simple derecho subjetivo no fundamental (Navarro, 2011. p. 41). Puesto que tiene su raíz en el derecho natural inherente a toda persona, continente de leyes anteriores a las originadas y emanadas por el acuerdo (positivas) permitiendo situar la libertad de conciencia, que es su principio y fundamento, por encima del Estado frente a normas injustas (Mosquera, 2005, pp.162163; Mansilla y Villarán, 2000, p.22, y Tejada, 2010. p.40), estamos de acuerdo con Mosquera.

La Objeción de Conciencia implica una resistencia del individuo ante el cumplimiento de una norma cuando entre

\footnotetext{
1860, estableciéndose la libertad de cultos. De lo que se destaca la participación positiva de la Iglesia para el progresivo reconocimiento de la libertad de conciencia. Vestigio de esta regulación se encuentra manifestado en el $3^{\circ}$ párrafo del Art. 14 de la CPP de 1993 cuando reza respecto a la enseñanza de la educación religiosa: "se imparte con respeto a la libertad de las conciencias", como si esta libertad fuera el soporte de la libertad religiosa, lo cual ahora resulta inaceptable.
} 
en conflicto con sus propias convicciones (Mosquera, 2005, p.163; Fernández, s.a, p.215), de carácter ético, político, filósofo, etc. En su faz negativa implica la existencia de una esfera de inmunidad de coacción para el cumplimiento de la norma que el objetor considera contraria a su conciencia. Ello excluye de un modo absoluto toda intromisión estatal de la que pueda resultar una elección forzada de una determinada convicción. Quien objeta tiene a su favor una presunción de corrección moral, según lo cual no se puede obligar a nadie a actuar en contra de sus convicciones, salvo que se trasgreda el orden público, o cuando se lesionan valores sustantivos generales (Talavera, 2011, p, 2)

\section{B) Características de la Objeción de conciencia}

La primera característica existente para considerar a una conducta que merece la protección de la objeción de conciencia es que se objeta en conciencia una norma de Derecho (Martínez y Ponce, 2007, p, 85) en cualquiera de las modalidades que esta adopte, abarcando tanto preceptos de índole legal, jurisdiccional o contractual (tutelado por la ley), para omitir el cumplimiento de una obligación jurídicamente exigible (Talavera, 2011, p. 7), cuyos deberes se dirigen directamente a la persona que objeta (Aparisi y López, 2010, $p, 5)$. Por tanto, la objeción de conciencia va exclusivamente contra la obligatoriedad de la norma para el objetor (Millan, 1990, p. 19). Esto consiste en un deber jurídico (Arrieta, citado por Martínez y Ponce, 2007, p, 86).

La segunda característica es que el comportamiento demandado por el objetor ha de ser omisivo al cumplimiento de un deber. La excepción para su cumplimiento no significa que deje de ser un deber jurídico, pues con la objeción no se pretende modificar deber jurídico alguno (López y Aparisi, 2002, pp. 159-162). Con la objeción de quiere de una manera pacífica el respeto por las convicciones éticas, personales (Sánchez, 2009, p. 12).

La tercera, que el núcleo del comportamiento omisivo se apoya en motivaciones religiosas, éticas, morales o axiológicas. La contradicción a la norma es secundaria a estas (López y Aparisi, 2002, pp. 159-160). El efecto de la omisión es la prevalencia de una norma moral frente a una norma jurídica. Se trata de un conflicto entre imperativos éticos, que surgen de la conciencia, e imperativos normativos (Martínez y Ponce, 2007, p, 85).

La cuarta, que la legitimidad para ejercer la objeción de conciencia se pierde cuando entra en conflicto con otros derechos y bienes fundamentales que se afectarían si el objetor continuara con su actitud omisiva. Por ello a decir de Cañal, citado por (López y Aparisi, 2002) “El objetor está legitimado para incumplir un deber jurídico, pero no para lesionar los derechos ajenos, obligarles a compartir su criterio o utilizar a los demás como instrumentos" ( $p$. 160).

La quinta característica consiste en que es personal. La voluntad de la persona que objeta es insustituible en sus dos momentos: el de la toma de la decisión por la norma de conciencia y el de la manifestación externa de la oposición a la norma por razones de conciencia (Martínez y Ponce, 2007, p. 85).

\section{C) La Objeción de Conciencia en el Perú}

En nuestro país, el derecho de objeción de conciencia puede ser ejercido sin la necesidad de una regulación expresa, por ejemplo, una Ley que desarrolle este derecho con respecto al servicio militar. 
El art. 4 de la Ley de Libertad Religiosa que: "La objeción de conciencia es la oposición de un individuo al cumplimiento de un deber legal, en razón de sus convicciones morales o religiosas. Se ejerce la objeción de conciencia cuando alguien se ve imposibilitado de cumplir una obligación legal por causa de un imperativo moral o religioso, grave o ineludible, reconocido por la entidad religiosa a la que pertenece" ${ }^{118}$. Si bien es cierto, esta Ley, y su respectivo Reglamento facultan al ejercicio del derecho a la Objeción de Conciencia por razones religiosas, no limita dicho derecho al ámbito religioso, dado que también es la materialización de los derechos a la libertad de conciencia y pensamiento reconocidos por la Constitución Política del Perú. Por este motivo, el Tribunal Constitucional peruano considera que la objeción de conciencia es un derecho de excepción, expresión de los derechos constitucionales a las libertades de conciencia y religión, pues de nada serviría la regulación de estas libertades si no se establece un mecanismo que pueda efectivizarlas ${ }^{9}$. Por este motivo, ante un caso de objeción de conciencia por razones propias de conciencia o morales, no religiosas, el Tribunal encargado de la causa deberá analizarla casuísticamente, diferenciando adecuadamente las razones de conciencia de las de religión, determinando a su vez si hay una vulneración de estas libertades o no.

Por último, concordando con Mansilla y Villarán (2000), el mecanismo jurídico procesal que tiene como finalidad asegurar la vigencia y efectividad del derecho a la libertad de conciencia y/o religión es la

${ }^{8}$ Con el mismo tenor, el Reglamento de la Ley № 29635, Ley de Libertad Religiosa, Art. 8, sobre Objeción de conciencia por razones religiosas, prescribe lo siguiente: "8.1: La objeción de conciencia a que se refiere el artículo 4 de la Ley se fundamenta en la doctrina religiosa que se profesa, debidamente reconocida por la autoridad de la entidad religiosa a la que se pertenece, siempre que no atente contra los derechos fundamentales, la moral y las buenas costumbres. 8.2: Las entidades públicas y privadas toman las previsiones correspondientes para garantizar la atención necesaria en caso de petición de objeción de conciencia".

${ }^{9}$ Cfr. STC del 19 de agosto de 2002, Perú EXP. N. ${ }^{\circ}$ 0895-2001-AA/TC, Fundamentos jurídicos 5 y 6 . garantía procesal constitucional de Acción de Hábeas Corpus (art. 200 inc. 1 CPP-1993). La misma que procede contra el hecho $u$ omisión, por parte de cualquier autoridad, funcionario o persona que vulnera o amenaza la libertad individual o los derechos constitucionales conexos (pp. 110-116). Las libertades protegidas por la objeción son conexas a la libertad individual. Ello se verifica con el art. $12^{\circ}$ inc. $2^{\circ}$ de la Ley de Habeas Corpus y Amparo ${ }^{10}$. Por lo dicho, Si bien es cierto que el Art.24 Incic.3 de la misma ley establece para la acción de amparo que "procede en defensa de los siguientes derechos... del ejercicio público de cualquier confesión religiosa, siempre que no ofenda la moral y buenas costumbres" esto no debe confundirse con la libertad de religión que se debe proteger con el Habeas Corpus, pues la resguarda en su contenido amplio, mientras que el Amparo sólo se dirige a proteger el ejercicio público de dicho derecho, teniendo gran importancia la publicidad para poder invocarse en esta vía. (Chirinos, 2006, pp. 552-559).

La objeción de conciencia del profesional médico frente al Protocolo de Aborto Terapéutico

\section{A) Protección jurídica del concebido en la normativa peruana}

En el ordenamiento jurídico peruano hay una vinculación entre la noción de vida y la de ser humano. En el Perú, desde la vigencia de la precedente Constitución de 1979 (con mayor razón en la Carta de 1993), ha existido y existe una filosofía o tendencia finalista bastante acentuada, y que no es otra que "el personalismo". Por tal tendencia se entiende que el supuesto

\footnotetext{
${ }^{10}$ Art. 12: "Se vulnera o amenaza la libertad individual y en consecuencia procede la acción de Hábeas Corpus, enunciativamente, en los siguientes casos (...) 2) De la libertad de conciencia y de creencia".
} 
ideológico de fondo que fundamenta todo el engranaje constitucional y el propio ordenamiento jurídico que lo desarrolla es antes y por encima de todo: la persona (Sáenz, 2010, pp. 34-36). Así, el Artículo $1^{\circ}$ de nuestra Constitución Política de 1993 reconoce expresamente que "la defensa de la persona humana y el respecto de su dignidad son el fin supremo de la sociedad y del Estado", con lo cual se manifiesta que el Estado es para el hombre y no el hombre para el Estado.

El concebido tiene como principio de base el reconocimiento de su calidad de sujeto de derecho, de ser humano desde su concepción hasta su muerte. Dicha calidad aparece con un derecho innato del ser humano, inherente a su ser (Monge, 2003, p. 94; Flores, 2002, p. 149 y Vasallo, 2003, pp. 31-32). Por el hecho de existir todo ser humano es sujeto de derecho, es el fenómeno biológico de la vida humana el que desencadena la adquisición o la pérdida de la posibilidad de ser considerado como titular de derechos y obligaciones. Dicho tal, el reconocimiento del derecho a la vida del concebido reviste de una gran importancia, pues si bien es cierto que su protección se limita a los derechos de carácter extra patrimonial, bien es posible la reserva de sus derechos patrimoniales a condición de que nazca vivo (Exp. 1127-93, 2007. p. 36). El CC considera al concebido como ser independiente distinto de la madre (Espinoza, 2008, p. 196). Esto denota su capacidad actual de goce y capacidad potencial de ejercicio, de donde se cierra el margen de diferencia entre un ser pre natal y una persona nacida, razón por la cual se ve manifiesta la dignidad de ambos.

La Constitución de 1979 establecía que la persona humana es el fin supremo de la sociedad y del Estado. Todos tienen la obligación de respetarla y protegerla. Esta misma Constitución fue la primera que incluyó una norma relativa a la situación jurídica del nasciturus. En el inciso 1 de su Art. 2 enunciaba: "Toda persona tiene derecho: 1.- $A$ la vida, a un nombre propio, a la integridad física $y$ al libre desenvolvimiento de su personalidad. Al que está por nacer se le considera nacido para todo lo que le favorece". Es de observarse que abandonó la exigencia de que el concebido naciera vivo para considerar sus derechos (Vega, 1996, pp. 138-139; Monge, 2003, p. 94 y Fernández, 2004, p. 7). Lo cual ha representado un paso más para la protección jurídica del concebido.

Por su parte, el Código Civil de 1984 proporcionó una novedad, siendo el primero en el mundo que anticipa la subjetividad desde la concepción "para todo en cuanto le favorece" (Vega, 1996, pp. 141-143) $)^{11}$; y sobre todo porque hace remontar a la concepción el inicio de la vida humana, condicionando sólo la atribución irrevocable de los derechos patrimoniales al nacimiento con vida. Con ello se concentra la atención en el valor de la vida humana ${ }^{12}$, llega a utilizar una conceptualización abstracta para la defensa del ser concreto de los concebidos (Vega, 1996, pp. 143-144 y Mosset, 2002, pp. 197-218).

De otro lado, Código de los Niños y Adolescentes (Ley $\mathrm{N}^{\circ}$ 273337) no distingue entre concebido y persona humana, pues considera niño a todo ser humano desde su concepción hasta los 12 años, confiriéndole la calidad de sujeto de derecho y le reconoce su capacidad jurídica para ser titular,

\footnotetext{
${ }^{11}$ Ello lo constatamos a través de los derechos reconocidos dispersamente en el articulado del Código Civil, tales como Art. 2, que al permitir a la mujer solicitar judicialmente el reconocimiento del embarazo o el parto, con citación de los que tengan interés en el nacimiento, tutela lo relativo a la filiación y a la herencia; el artículo 598 que alude a la representación del nasciturus si el padre muere y la madre está destituida de la patria potestad; a la herencia (Art. 805 inciso 1); a la indivisibilidad de la herencia hasta su nacimiento (Art. 856).

${ }^{12}$ A efectos ilustrativos, Art. $1^{\circ}$ CC. 1984: "La persona humana es sujeto de derecho desde su nacimiento". La vida humana comienza con la concepción. El concebido es sujeto de derecho para todo cuanto le favorece. La atribución de derechos patrimoniales está condicionada a que nazca vivo."
} 
además de los derechos inherentes a la persona humana, de los derechos específicos relacionados con su proceso de desarrollo, así, entre otros y sin pretender ser extensivos se tiene el Artículo $1^{\circ}$ de dicho Código, el cual prescribe que "Todo niño tiene derecho a la vida desde el momento de la concepción". El Decreto Legislativo 346 o Ley de Política Nacional de Población establece en el artículo IV, inciso I de su título preliminar que "La Política Nacional garantiza los derechos de la persona humana: A la Vida -y que- el concebido es sujeto de derecho desde la concepción".

Al igual que con la normativa del Código Civil, observamos que la concepción es el hecho crucial con el cual empieza la protección jurídica de la vida, el Ordenamiento jurídico peruano no pone en tela de juicio el inicio de la concepción, por asumir, de los argumentos normativos aportados, que esta se da desde la unión de los dos gametos humanos. Por último, la Ley General de Salud del 20 de Julio de 1997 (Ley No 26842), cuyo artículo III de su título preliminar prevé que el concebido es sujeto del derecho a la salud en las condiciones que prevea la ley. De la normativa expuesta podemos concluir que en el Perú se resguarda el derecho a vivir del concebido, pues aunque desde el punto de vista natural es un ser enclaustrado que está en formación y que biológicamente depende de su madre para poder subsistir lo relevante es que desde la perspectiva jurídica nacional el concebido (persona por nacer) es un centro de imputación jurídica del mismo modo que lo es la persona nacida, ello debido a que la vida humana es una sola, ya sea antes o después del nacimiento.

\section{B) El aborto terapéutico según el Protocolo de aborto Terapéutico (PAT)}

La denominación aborto "aborto terapéutico" ha sido empleada para aquellos casos de la práctica médica en donde la vida - la salud de la mujer gestante corren un grave peligro durante el embarazo. Sin embargo, la combinación de las palabras "aborto" y "terapia", generan un contra sentido.

Una de las condiciones para determinar el carácter terapéutico de un acto médico consiste en que la intervención médica se dirija a curar o retirar la parte del cuerpo dañada por la enfermedad. Con el aborto terapéutico se busca la extracción del feto, organismo que puede estar sano, para evitar el peligro de muerte o de una enfermedad de la mujer gestante, siendo una acción que no se dirige contra la enfermedad. Resulta inadecuado el adjetivo "terapéutico", dado que no se trata de una terapia (Sgreccia, 2009, pp. 563-564 y Bessio, 2008, p. 9) ${ }^{13}$.

Pese a la incoherencia entre lo que se denomina como aborto terapéutico y el significado de la terapia, se viene permitiendo la realización de este tipo de abortos, la misma que resulta problemática, por extensiva. A decir de Ortiz y Maqueda (2012):

“...se presta a numerosas interpretaciones, dado que el propio concepto de "salud" es multívoco y omnicomprensivo. Esta imprecisión del concepto puede ocasionar que la práctica amplíe exageradamente la causal, permitiendo la realización de abortos por alegadas razones de salud

\footnotetext{
13 Por su parte, Tullio, citado por Martín, 2005, p. 146, expone su comprensión sobre lo que implica una terapia: "... actividades, maniobras, procedimientos, comúnmente manuales, instrumentales u orales, con los cuales se intenta aliviar, reparar, curar o rehabilitar una enfermedad psicofísica, orgánica o funcional, o mejorar el aspecto estético de una persona". Asimismo López, 2012, p. 572. al analizar las consecuencias de un aborto en la mujer, explica sobre una alteración psiquiátrica verificable en las mujeres que han abortado, denominada "estrés postraumático". La cual afecta peligrosamente a la salud emocional de la mujer incrementando su propensión al suicidio. Concluye que un aborto nunca será una medida terapéutica para la mujer. En otras palabras, con la muerte intencionada del feto, la madre no recuperará la salud, sino que podría sufrir el trastorno en mención
} 
"social" o "emocional", pudiendo así todo aborto ser encuadrado en tales supuestos..." (p. 48) $)^{14}$.

El aborto terapéutico aparentemente encuentra su justificación en la salud de la madre gestante, sin embargo, la salud no es un bien moral en sí mismo. Para que sea comprendida de esta forma ha de verse en relación a la vida que le da sentido. Por lo que es totalmente inmoral el sacrificio de la vida a cambio de conservar la salud, pues en este caso se está prefiriendo un bien físico (salud) a un bien moral, como lo es la vida (Pérez, 2009, p. 99). Asimismo, bajo la invocación de la salud, el criterio para la aceptación de esta clase de aborto puede reducirse a cifras estadísticas. Algunos autores consideran que según las ciencias genética y embriológica humanas sólo el $20 \%$ de los cigotos sobreviven a la primera fase del embarazo, llegando a la etapa de feto. Razón por la cual no se le puede otorgar derechos antes de haber nacido (Piekarenwicz, 2015, p. 7).

El aborto terapéutico presenta dos casos dramáticos, en los que el médico se ve tentado a aconsejar un aborto intencionado para salvar a la madre, con lo que entienden que una de las dos vidas humanas, la de la mujer, es más importante (Sgreccia, 2009, p. $571)^{15}$, lo cual resulta discriminatorio. Esto vulnera la dignidad humana de toda persona, la misma que exige tratar a cada hombre como un fin y no como un medio, no pudiendo decidirse sobre su origen o su fin, desarrollo o carencias. Por ello, y con razón Di Pietro (s. sostiene que el aborto

\footnotetext{
${ }^{14}$ Esto es notorio en diversas publicaciones, como la de Gispert (2005) que establece como uno de sus principios para la interrupción voluntaria del embarazo, por razones terapéuticas, el que se evidencie un "... grave daño físico, mental o social de la madre en caso de continuar el embarazo." Extendiendo esta causal a contextos no sanitarios (p. 143).

15 Sin duda, no puede haber excepciones al valor "vida", aunque haya diversas denominaciones atribuidas a determinados seres humanos para justificar el acto de darles muerte: cuando se dice que sus vidas son un "valor subordinado", o una "vida sin valor", o una "vida no plenamente humana". Aceptar esta clase de justificantes daría lugar a prácticas como la eutanasia u otra clase de procedimiento discriminatorio.
}

procurado siempre será inmoral, por su finalidad (p. 55).

Un caso consiste en que la continuación del embarazo ocasionaría la muerte de la madre con imposibilidad de salvar al niño. Aquí hay algunas motivaciones que intentan justificar la muerte directa del feto.

Tenemos la motivación del conflicto de deberes. El médico es consciente de su deber de trabajar para salvar la vida de ambos, pero ante la imposibilidad médica de lograrlo, escoge el deber más accesible. En este caso sería el de salvar la vida de la madre, que depende involuntariamente de la muerte del feto, al cual el médico decide, con pesar, dar muerte directamente.

También tenemos la motivación de la calificación subordinada del feto ya condenado. Considera que el feto está condenado a morir por sí mismo, ya que las condiciones biológicas que requiere no le favorecen. Sin embargo, no puede justificarse, pues es distinta una muerte natural a una muerte intencional.

Otra, es la motivación de la valoración global. Bajo la consideración de la globalidad del problema asistencial en la relación madre-niño, también sería global la actividad del médico responsable, quien busca salvar lo que sea posible, ya que se encuentra médicamente imposibilitado de salvar todo. Esta motivación es criticada porque el compromiso de salvar la vida de la madre no justifica el matar directamente al feto.

Otra motivación consiste en el carácter no absoluto de la norma. Considera que hay excepciones que justifican el incumplimiento de la norma que prohíbe matar (ej. legítima defensa). Este razonamiento no podría aplicarse para el caso de dar muerte al feto, 
ya que es una vida inocente y no un agresor injusto (Sgreccia, 2009, pp. 569 - 571).

En todas estas dramáticas motivaciones, la vida que se sacrifica es la del feto. Ello se debe a la falta de integración entre los aportes de la ciencia biológica y la antropología filosófica al momento de valorar la vida humana. La ciencia tiene resuelta la cuestión sobre la consideración del cuerpo del embrión. Sostiene que el ser concebido de progenitores humanos es un cuerpo humano. Asimismo, la ciencia conoce el valor de la vida incipiente (al igual que de la vida a término) y aporta en la cuestión del carácter personal de cada cuerpo humano. Lo impredecible para comprender ambas cuestiones es conocer que la corporalidad constituye a la persona. Esta, la persona, existe en un cuerpo, es su cuerpo, a lo largo de su trayectoria existencial (López, 2011, pp. $284-285$ ).

La evaluación ética de los argumentos que "justificarían" el aborto terapéutico deberá realizarse dentro de una visión personalista. Se debe reconocer que el principio ético fundamental es la persona humana, cuyo valor es máximo y supera a cualquier otro bien. Nada puede estar subordinada a ella, ni las razones sociales, económicas ni de otra índole, tiene una calidad ontológica y axiológica anterior a la misma sociedad (Sgreccia, 2009, pp. 567 568).

Al contrario de realizar un aborto directo, existe el deber del médico de procurar, con todos los medios terapéuticos, salvar ambas vidas: el feto y la mujer) (Sgreccia, 2009, p. 571). A la luz de este deber, la pérdida no querida de la vida del feto tiene una connotación ética, médica y lícita. Se trata de un aborto indirecto, en el que el tratamiento médico escogido es una acción con doble efecto ${ }^{16}$ : uno directo, la curación de la enfermedad, y otro indirecto, la pérdida del feto (Lucas, 2005, p. 146). No se busca la consecuencia negativa: la muerte del feto (Herrera, 1999, pp. 250-257). Este muere como efecto no querido de la realización de una terapia dirigida a salvaguardar, también, la vida de la madre, por ejemplo la extirpación de un tumor uterino. Aquí se respeta el principio ético por excelencia: el reconocimiento del embrión como una persona merecedora del respeto por su vida, pese a sus limitaciones fisiológicas (Bessio, 2008, p. 10).

Consideramos que este es el sentido en el que se debe entender la despenalización del aborto terapéutico, que no reprende por la consecuencia de la muerte de la vida humana intrauterina, ni tampoco la celebra, reconociendo un derecho al aborto.

La doctrina del doble efecto, entendida correctamente, se vincula con el principio de totalidad o terapéutico de la bioética personalista. Sin embargo, es preciso acotar que este principio es inaplicable para las decisiones que repercutan sobre una mujer embarazada, ya que este opera en la medida que en la aplicación de los tratamientos se corre el riesgo de sacrificar alguna parte del cuerpo de la madre, a fin de salvaguardarla de morir o de sufrir daños graves que la afectarían del todo para el resto de su vida (Sgreccia, 2009, pp. 224-225) ${ }^{17}$, no obstante, el feto no es una parte de la madre, es una persona independiente de ella.

\footnotetext{
${ }^{16}$ Para más detalles sobre la doctrina del doble efecto, sugerimos revisar: Pérez, 2017, p. 54-56.

${ }^{17}$ Este autor explica que: "El mismo principio - de totalidad o terapéuticopuede tener aplicaciones más relevantes cuando se trata de extirpar tumores, de operaciones de riesgo y de intervenciones que pueden comportar menoscabos importantes como la esterilización terapéutica, por ejemplo como consecuencia de la extirpación de un tumor uterino. En estos casos, el daño que acompaña a una intervención directa con otra finalidad lícita u obligada es considerado éticamente aceptable, según del criterio "voluntario indirecto".
} 
El PAT, es la "Guía Técnica Nacional para la estandarización del Procedimiento de la Atención Integral de la gestante en la Interrupción Voluntaria por indicación terapéutica del embarazo menor de 22 semanas con Consentimiento Informado en el Marco de lo dispuesto en el Artículo 119 del Código Penal", por lo que desarrolla el procedimiento que se debe realizar en un hospital cuando, por indicación terapéutica, la mujer gestante brinde su Consentimiento Informado para la realización de un aborto, según la eximente de responsabilidad penal que regula el art. 119 del Código Penal. El PAT debería ser coherente con dicho artículo, que contempla: "No es punible el aborto practicado por un médico con el consentimiento de la mujer embarazada o de su representante legal, si lo tuviere, cuando es el único medio para salvar la vida de la gestante o para evitar en su salud un mal grave y permanente".

Si hubiese dicha coherencia, resultaría poco probable que un médico objete por motivos de conciencia el aplicar toda su ciencia y ética médica para salvaguardar la vida de la madre gestante y de la persona en desarrollo pre natal, siendo consciente de que en el intento existe la posibilidad de perder la vida del segundo, al tratarse del ser humano más vulnerable.

En este orden de ideas, y como se ha venido aplicando el Art. $119 \mathrm{CP}$ desde su promulgación, la Ley penal no impone una pena por su realización, y en consecuencia, exonera de la pena correspondiente, tanto a la mujer que consienta la realización del aborto terapéutico, como al profesional médico que lo realice ${ }^{18}$.

\footnotetext{
${ }^{18}$ Desde el punto de vista jurídico, dicha exoneración se debe a que el aborto es una acción tipificada como delito, pero al tener la denominación de terapéutico, se comprende que no sea antijurídica, ya que cuenta con razones especiales, al ser un estado de necesidad justificante, según lo regulado por el Inc. 4 del Art. 20 del Código Penal. Un análisis detallado sobre el aborto terapéutico según el art. 119 del código penal lo encontramos en: Pérez, 2017, pp. 106-121.
}

En cuanto a la mujer gestante, la redacción del art. 119 Código Penal hace inaplicable la pena impuesta en el art. 114 del mismo: pena privativa de la libertad no mayor de dos años, o prestación de servicio comunitario de cincuentidós a ciento cuatro jornadas. Por su parte, el médico que ejecute el aborto terapéutico queda exonerado de la pena correspondiente al delito de aborto agravado por cualificación del sujeto activo, que se aplica para el profesional que emplee sus habilidades y capacitación para causar un aborto, exonerándosele de la pena privativa de libertad de uno a cinco años por la realización del delito de aborto ${ }^{19}$. Además, lo libra de la pena de inhabilitación del ejercicio profesional referida por el art. $117 \mathrm{CP}$, que se generaría en el caso de la realización de abortos no terapéuticos, dado el abuso de la profesión. Dicha inhabilitación es de tipo accesoria, dado que acompaña a la pena privativa de libertad del profesional ${ }^{20}$, que incumpla el deber especial de proteger la vida humana, y su duración equivale al tiempo asignado para la pena privativa de la libertad.

No obstante lo dicho, tanto el título del PAT, como su contenido, al referirse al aborto por "indicación terapéutica" regula un aborto directo, ya que se trata de la "interrupción voluntaria del embarazo". Es un aborto provocado, intencionado, consentido, y no una terapia. La intencionalidad para el aborto se evidencia su art. 6 inc. 2.2, cuando regula la sobre la decisión de la gestante de realizarse el

\footnotetext{
19 Art. 117: "El médico, obstetra, farmacéutico, o cualquier profesional sanitario, que abusa de su ciencia o arte para causar el aborto, será reprimido con la pena de los artículos $115^{\circ}$ y $116^{\circ}$ e inhabilitación conforme al artículo $36^{\circ}$, incisos 4 y $8^{\prime \prime}$. Art. 115: "El que causa el aborto con el consentimiento de la gestante, será reprimido con pena privativa de libertad no menor de uno ni mayor de cuatro años. Si sobreviene la muerte de la mujer y el agente pudo prever este resultado, la pena será no menor de dos ni mayor de cinco años." Art. 116: "El que hace abortar a una mujer sin su consentimiento, será reprimido con pena privativa de libertad no menor de tres ni mayor de cinco años. Si sobreviene la muerte de la mujer y el agente pudo prever este resultado, la pena será no menor de cinco ni mayor de diez años".

${ }^{20}$ Art. 39: "La inhabilitación se impondrá como pena accesoria cuando el hecho punible cometido por el condenado constituye abuso de autoridad de cargo, de profesión, oficio... Se extiende por igual tiempo que la pena principal."
} 
aborto "A petición de la gestante el médico/a tratante presenta la solicitud escrita del caso..." y el art. 6 inc. 2.4, que manifiesta la cooperación voluntaria en la realización del aborto por parte del profesional de la salud "... En caso que la Junta Médica apruebe la interrupción del embarazo..." y la firma de la gestante o de su representante legal del formulario de $\mathrm{Cl}$, autorizando la realización del procedimiento. Asimismo, con el art. 6 inc. 3.4 se faculta a la gestante a solicitar la revisión de su petición de aborto ante una nueva Junta Médica cuando la anterior haya considerado que dicha realización no es recomendable.

Aunque se manifieste la complicación con la cual el PAT justifica el aborto "cuando es el único medio para salvar la vida de la gestante o para evitar en su salud un mal grave y permanente", esta situación concreta y dolorosa no vuelve al aborto directo en ético, ya que ninguna persona puede ser usada como medio para salvar a otra, ambas vidas tienen el mismo valor. Igualmente, la eliminación directa de la vida intra uterina no puede justificarse éticamente, mediante la aplicación de la doctrina del doble efecto, ya que el efecto inmediato de dicho aborto es el malo: muerte del feto, y no el bueno como lo requiere este principio. Por estos motivos, es probable que el profesional médico quiera abstenerse de realizar el aborto terapéutico regulado en el PAT, como veremos en el siguiente apartado.

\section{C) Objeción de conciencia médica ante el Protocolo de Aborto Terapéutico}

Las razones morales tienen un pilar dado a conocer por la razón natural. Es de ahí que la trasgresión de la libertad de conciencia genera graves consecuencias sobre la persona que realiza una acción que repudia obligada por un deber jurídico determinado, de allí se advierte la importancia de protegerla y el crucial papel que adquiere el derecho de objeción de conciencia frente a un ordenamiento jurídico que por diversas razones inobserva el contenido de la naturaleza humana.

El conflicto entre la norma jurídica y la norma de conciencia que exige el respeto por la vida humana se da siempre que su vulneración se encuentre permitida en algún momento del desarrollo vital, desde la fecundación hasta su muerte natural, por lo que es posible la objeción en conciencia del profesional médico a la realización de un aborto directo, según el tenor del PAT. La objeción de conciencia propiamente dicha se dará cuando dicho profesional declare que no tiene la obligación de ejecutar un aborto, aunque cuente con el consentimiento informado de la mujer gestante, en razón de sus convicciones personales, sin otra justificación como la legal (Hoyos, 2006, p. 81) o la científica. Es decir, el médico bien sabe por ciencia que la realización del procedimiento abortivo redactado en el PAT implica la eliminación directa de la vida humana en desarrollo intrauterino, tratándose de un aborto directo, pero no emplea sus argumentos para incumplir el deber de practicarlo, sino en el atentado que realizar ese acto se generaría en contra de su persona, de sus convicciones éticas y morales.

Este derecho ha de ejercerse en todas las circunstancias donde haya un conflicto de deberes: jurídicos y morales. No obstante, como todo derecho tiene sus límites, situación que parece complicada, ya que para ello hace falta una adecuada percepción e información sobre las convicciones personales de quien pretenda ser objetor. 
Una parte de la doctrina considera la "necesidad de sopesar la carga que supone para el objetor verse coartado en su autonomía o libertad y las repercusiones que para otras personas o para la sociedad puede tener su exención de determinada acción" (Hoyos, 2006, p. 81), de manera que después de la realización de un juicio de ponderación de intereses se prefiera uno (el que sea menos lesivo para la persona) sobre el otro, bajo la previa consideración de núcleo central de los derechos que se exigen, o se escoja, en el caso de existir, una solución distinta que no perjudique a nadie o lo haga mínimamente, por ejemplo, para el caso de los objetores que se vean imposibilitados por razones de conciencia a cumplir con el deber de realizar un juramento para determinadas circunstancias se ha optado por una fórmula alternativa, lo cual servirá para evitar que se generen desigualdades y disuadir a los falsos objetores.

Otro sector de la doctrina, al cual nos adherimos, sugiere que se deberá analizar la objeción en consideración a un caso en concreto, para ver hasta dónde llega, considerando, según sostienen otros autores, al derecho de objeción de conciencia, como un derecho fundamental cuyo único límite lo constituye el orden público, la seguridad y la igualdad (Hoyos, 2006 , p. 8). Nos parece que la objeción de conciencia debe analizarse casuísticamente siempre, ya que tratar de limitar este derecho a una prescripción general -normapara ejercerlo ya implica una vulneración al ejercicio de la libertad de conciencia.

\section{Conclusiones}

En el Perú, la Objeción de Conciencia se ha entendido como una manifestación de la libertad de conciencia. Se trata de un concepto que viene desarrollándose paulatinamente. En principio la Constitución Política del Perú reconoce el derecho a la libertad de conciencia de todas las personas. Hasta el momento, la jurisprudencia la ha reconocido con la consideración de derecho fundamental a través de la capacidad interpretativa de los jueces. En las sentencias del TC se viene sosteniendo que la Objeción de Conciencia es una excepción a una norma general, que deberá reconocerse en cada caso concreto, y no de manera automática.

- El Ordenamiento Jurídico peruano reconoce y protege la vida de la persona humana desde la concepción. Una interpretación coherente de la Constitución Política, el Código Civil, el Código de los Niños y Adolescentes, la Ley de Política Nacional de Población, y la Ley General de Salud del 20 de Julio de 1997, permite conocer el sentido proteccionista de sus normas. Ello se corrobora, además, en la última jurisprudencia emitida por el TC en la sentencia del expediente $\mathrm{N}^{\circ}$. 2005-2009PA/TC de fecha 16 de octubre del año 2009. En este pronunciamiento se prohibió que el MINSA distribuya gratuitamente la PDS en el sector público. Incluyó, lamentablemente, sólo a este sector y no al sector privado atendiendo a ciertos criterios procesales que impiden a los jueces un pronunciamiento en la sentencia que exceda a lo solicitado por el demandante. Además dicha sentencia tuvo como fundamento la duda científica razonable que existe sobre el efecto abortivo de la PDS. A la luz de los principios pro-homine, pro débiles $y$ precautorio, el TC ha manifestado su disconformidad con el uso de la PDS hasta que se descarte científicamente el mencionado efecto abortivo. En este sentido, el TC se encuentra acorde con 
el criterio de proteger la vida humana desde la fecundación.

La legislación nacional sobre el aborto terapéutico parte desde la despenalización del mismo, regulada en el art. 119 del Código Penal. Dicho aborto, es un hecho antijurídico que se encuentra exonerado de la pena correspondiente al delito de aborto, cuando ocurre la circunstancia específica en que peligre la vida o la salud, de manera grave y permanente, de la madre gestante. Está justificado por un estado de necesidad exculpante, debido a que los bienes jurídicos implicados (la vida de la madre y la de su hijo en desarrollo) tienen el mismo valor. Por lo dicho, los bienes jurídicos objeto de la amenaza deben estar enumerados en una lista cerrada, lo cual no es tenido en cuenta por el Protocolo de Aborto Terapéutico, que permite una lista abierta de entidades clínicas por las cuales se podría abortar (art. 6 inc. 1.11), incumpliendo su presupuesto de que sea "el único medio" (art. 2), y, en consecuencia, legalizando abortos directos, no inmersos en el art. 119 del Código Penal.

La Objeción de Conciencia del personal médico a la realización de abortos terapéuticos en los términos del PAT es posible, debido a que no está obligado a obedecer una norma que atente directamente contra el principio ético y profesional de respetar y salvaguardar a toda vida humana, y no eliminarla.

\section{Bibliografía}

\section{Libros y artículos de revistas:}

Bessio, M, Chomalí, F, et al. (2008). Aborto "terapéutico": consideraciones médicas, éticas, jurídicas y del magisterio de la Iglesia Católica. Chile: Pontificia Universidad Católica de Chile.

Chirinos, E, y Chirinos, F. (2006). La Constitución: lectura y comentario. Perú: Rodhas.

Di Pietro, M. (s.a.). Aborto: dalla manipalazione della scienza alla manipolazione delle parole. Collana: Viverein

Espinoza, J. Derecho de las personas. (2008). Perú: Rodhas.

Fernández, A. (s.a). Objeción de conciencia y descanso semanal. Lima: UPC

Fernández, C. (2004). Derecho de las personas: exposición de motivos y comentarios al libro Primero del Código Civil peruano. Lima: Grijley.

Flores, P. (2002). Diccionario jurídico jundamental. Lima: Grijley.

Gispert, J. (2005). Conceptos de bioética y responsabilidad médica. México: Manual Moderno

Herrera, F. (1999). El derecho a la vida y el aborto. Santa Fe de Bogotá: Universidad del Rosario.

Hervada, J. (2005). Introducción crítica al Derecho Natural. Madrid: Aranzadi Civitas

Hoyos, I. (2006). Problemática jurídica de la objeción de conciencia: de nuevo sobre el fallo del aborto. Persona y Bioética, 10 $\left(\mathrm{N}^{\circ} 26\right), 69-84$

Llamazares, D. (1997). Derecho de la libertad de conciencia l: libertad de conciencia y laicidad. Madrid: Civitas. 
López, J, y Aparisi, Á. (2002). La píldora del día siguiente: aspectos farmacológicos, éticos y jurídicos. Lacaja

López, N. (2012). ¿Cómo cambia un aborto el cerebro?, Cuadernos de Bioética. 2(23), $565-584$.

López, N. (2011). Inicio de la vida de cada ser humano ¿Qué hace humano el cuerpo del hombre? Cuadernos de Bioética. 2(22), $283-308$.

Lucas, Ramón. (2005). Explícame la bioética: guía explicativa de los temas más controvertidos sobre la vida humana. Madrid: Palabra.

Mansilla, K, y Villarán, L. (2000). La objeción de conciencia: Un aporte a su comprensión y desarrollo en el Perú. Perú: Ceapz.

Martín, I. (2005). Bioética, religión y salud. Madrid: Subdirección general de bioética y orientación sanitaria.

Martínez, J y Ponce, A. (2007). El saber filosófico. México: Siglo XXI editores.

Millan, A. (1990). La objeción de conciencia. Madrid: Tecnos.

Monge, Luz. (2003). En Código Civil Comentado: por los 100 mejores especialistas. Lima. Gaceta Jurídica, Tomo I, 93-102.

Mosquera, S. (2005). El derecho de libertad de conciencia y de religión en el Ordenamiento Jurídico peruano. Piura: Palestra Editores S.A.C.

Mosset, J. (2002). El valor de la vida humana. Buenos Aires: Rubinzal-Culzoni editores.
Navarro, R, Martínez, J. (2011). Conflictos entre conciencia y ley: las objeciones de conciencia. Madrid: Iustrel.

Ortiz, D, y Maqueda, L. (2012). "Estados Unidos Mexicanos" en Defendiendo el derecho humano a la vida en Latinoamérica. México: Americans United For Life, 46 62.

Pérez, J. (2009). "El bien de la vida y el bien de la salud: el deber de preservarlos" en Junto al enfermo incurable $y$ al que muere: orientaciones éticas y operativas. Madrid: Pontificia Academia Pro Vita.

Piekarenwicz, M. (2015). Bioética, aborto y políticas públicas en América Latina. Revista de Bioética y Derecho, (33), 3-13.

Sáenz, L. (2010). "Las dimensiones del derecho a la vida" en Los derechos fundamentales. estudio de los derechos constitucionales desde las diversas especialidades del Derecho. Lima: Gaceta Jurídica.

Sánchez, I. (2001). "El derecho a la formación de la conciencia en el ordenamiento jurídico internacional" en Congreso latinoamericano sobre libertad religiosa. Lima: Pontificia Universidad Católica del Perú.

Sgreccia, E; Laffite, J. (2009). Junto al enfermo incurable $y$ al que muere: orientaciones éticas y operativas. Traducido por: Vives, L, y López, M. Madrid: Biblioteca de autores cristianos.

Vasallo, D. (2003). El derecho a la vida del concebido frente a la píldora del día siguiente. Brújula, 96(7).

Vega, Y. (1996). Derecho Privado. Tomo I. Lima: Grijley.

\section{Tesis:}


Pérez, B. (2017). Implicancias ético legislativas del Consentimiento Informado en la redacción del Protocolo de Aborto Terapéutico para la madre gestante (Tesis de maestría). Universidad Católica Santo Toribio de Mogrovejo, Chiclayo, Perú.

Sánchez, R. (2009). Libertad de conciencia en las técnicas de reproducción asistida y en las investigaciones biomédicas (Tesina para optar el grado de doctora). Madrid: Universidad Autónoma.

Tejada, R. (2010). Análisis de Expediente 27232001: La legalización o Interpretación del derecho de Objeción de Conciencia basada en creencias religiosas, frente a un eventual conflicto con el ius variando del empleador (Análisis de fin de carrera), Chiclayo.

\section{Legislación y jurisprudencia:}

Código de los Niños y Adolescentes.

Código Penal.

Constitución Política del Perú de 1823.

Constitución Política del Perú de 1860.

Constitución Política del Perú de 1933.

Constitución Política del Perú de 1979.

Constitución Política del Perú de 1993.

Convención Americana sobre Derechos Humanos de San José de Costa Rica.

Declaración Universal de Derechos Humanos.
Guía Técnica Nacional para la estandarización del procedimiento de la Atención Integral de la gestante en la Interrupción Voluntaria por indicación Terapéutica del Embarazo menor de 22 semanas con consentimiento informado en el marco de lo dispuesto en el artículo 119 del Código Penal.

Ley de Política Nacional de Población.

Ley de Habeas Corpus y Amparo.

Ley de Libertad Religiosa.

Ley General de Salud.

Pacto Internacional de Derechos Civiles.

Reglamento de la Ley de Libertad Religiosa.

Exp. 1127-93, Primera Sala Civil de la Corte Superior.

STC del 19 de agosto de 2002, Perú EXP. N. ${ }^{\circ}$ 0895-2001-AA/TC.

\section{Linkografía}

Aparisi, Á, y López, J. (2006). El derecho a la objeción de conciencia en el supuesto del aborto de la fundamentación filosóficojurídica a su reconocimiento legal. Recuperado de

http://www.um.edu.uy/docs/revistabiomedicina _nov_dic\%202009/bio_elderechoalaobjeci on.pdf

Talavera, P. (2010). La objeción de conciencia farmacéutica a la píldora postcoital. Recuperado de

http://www.aebioetica.org/rtf/La\%200bjecion\% 20De\%20Conciencia.rtf 